\title{
ОПРЕДЕЛЕНИЕ ИЗОМЕРНОГО СОСТАВА ПРОДУКТОВ РЕАКЦИИ РАСКРЫТИЯ БИЦИКЛООКСИРАНОВЫХ СИНТОНОВ ПРОСТАНОИДОВ МЕТОДОМ ВЫСОКОЭФФЕКТИВНОИ ЖИДКОСТНОИ ХРОМАТОГРАФИИ
}

Раскрытие эпоксида (1) нуклеофилами (3) ['] и (4) $\left.{ }^{1,2}\right]$, приводящее к кетондиолам (5) и (6), является универсальным методом получения простагландинов и их аналогов. Недавно нами показано $[3,4]$, что эпоксид (2), не вступающий во взаимодействие с нуклеофилом (4), легко реагирует с нуклеофилом (3), что позволяет получить интермедиаты карбациклина - ацетиленовые кетондиолы (7) и, после восстановления тройной связи, этиленовые кетондиолы (8) (структурные формулы и продукты синтеза приведены в таблице).

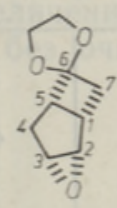

(1)

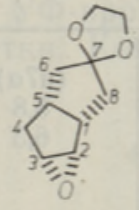

(2)

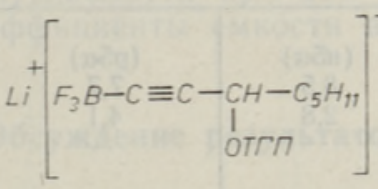

(3)

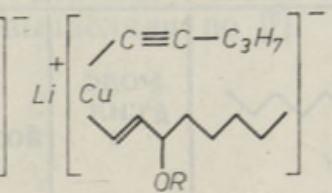

(4)

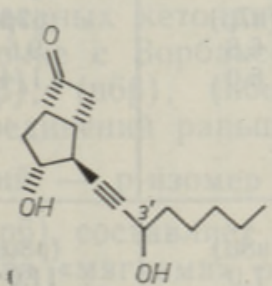

(H5).

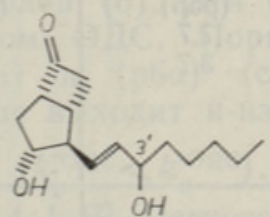

(H6)

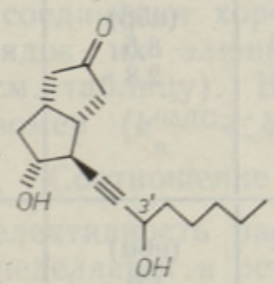

(H7)

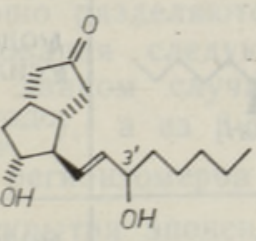

(

Целью настоящей работы было выявление возможностей разделения методом высокоэффективной жидкостной хроматографии (ВЭЖХ) регио- и стереоизомеров, образующихся при реакции раскрытия эпоксидов (1) и (2), и определение изомерного состава продуктов синтеза, т. е. степени регио- и стереоселективности этой реакции.

\section{Экспериментальная часть}

Методика проведения купратного раскрытия эпоксида (1) приведена в $\left[{ }^{1,2}\right]$ и боратного раскрытия эпоксида (2) - в [ $\left.{ }^{4}\right]$.

Методика раскрытия эпоксида (1) боратным реагентом (3). K 4,5 г 3 (1-тетрагидропиранилокси)окт-1-ина в 25 мл тетрагидрофурана (ТГФ) под аргоном добавляли при $-78^{\circ} \mathrm{C}$ за 15 мин 13 мл $1,6 \mathrm{~N}$ н-бутиллития 
в гексане и Һеремешивали в течение 10 мин. Затем добавляли $2, \overline{7}$ мл̈ (3 г) $\mathrm{BF}_{3} \cdot\left(\mathrm{C}_{2} \mathrm{H}_{5}\right)_{2} \mathrm{O}$ в 5 мл ТГФ, реакционную смесь перемешивали при $-78^{\circ} \mathrm{C}$ в течение 15 мин и добавляли 2,5 г этиленкеталя 3-оксатрицикло[4.2.0.0 2,4]октан-7-она (эпоксид (1)). После перемешивания при $-78^{\circ} \mathrm{C}$ в течение 30 мин реакционную смесь гидролизовали $10 \%$-ным раствором $\mathrm{NH}_{4} \mathrm{Cl}$, добавляли этилацетат, органический слой дважды промывали насыщенным раствором $\mathrm{NaCl}$ и сушили над $\mathrm{Na}_{2} \mathrm{SO}_{4}$. После отгонки растворителя сырой продукт фильтровали через силикагель (гексан:этилацетат 1:3) и деблокировали смесью ацетонитрил:вода:2N H $\mathrm{SO}_{4}(10: 4: 1)$ в течение 20 ч. После нейтрализации, экстракции и отгонки растворителей получили 1,48 г сырого продукта для анализа.

\section{Структурные формулы и коэффициенты емкости на колонках с Зорбаксом ОДС $\left(k^{\prime}\right.$ ОДС) и Зорбаксом СиЛ $\left(k^{\prime}\right.$ сил) исследуемых кетондиолов}

Условия хром атографирования: Зорбакс СИЛ, $4,6 \times 150$ мм, гексан:изопропанол $90: 10, T 35^{\circ} \mathrm{C}$, скорость потока 36 мл/ч; Зорбакс ОДС, 4,6×150 мм, ацетонитрил : вода $30: 70, T 35^{\circ} \mathrm{C}$, скорость потока 36 мл/ч.

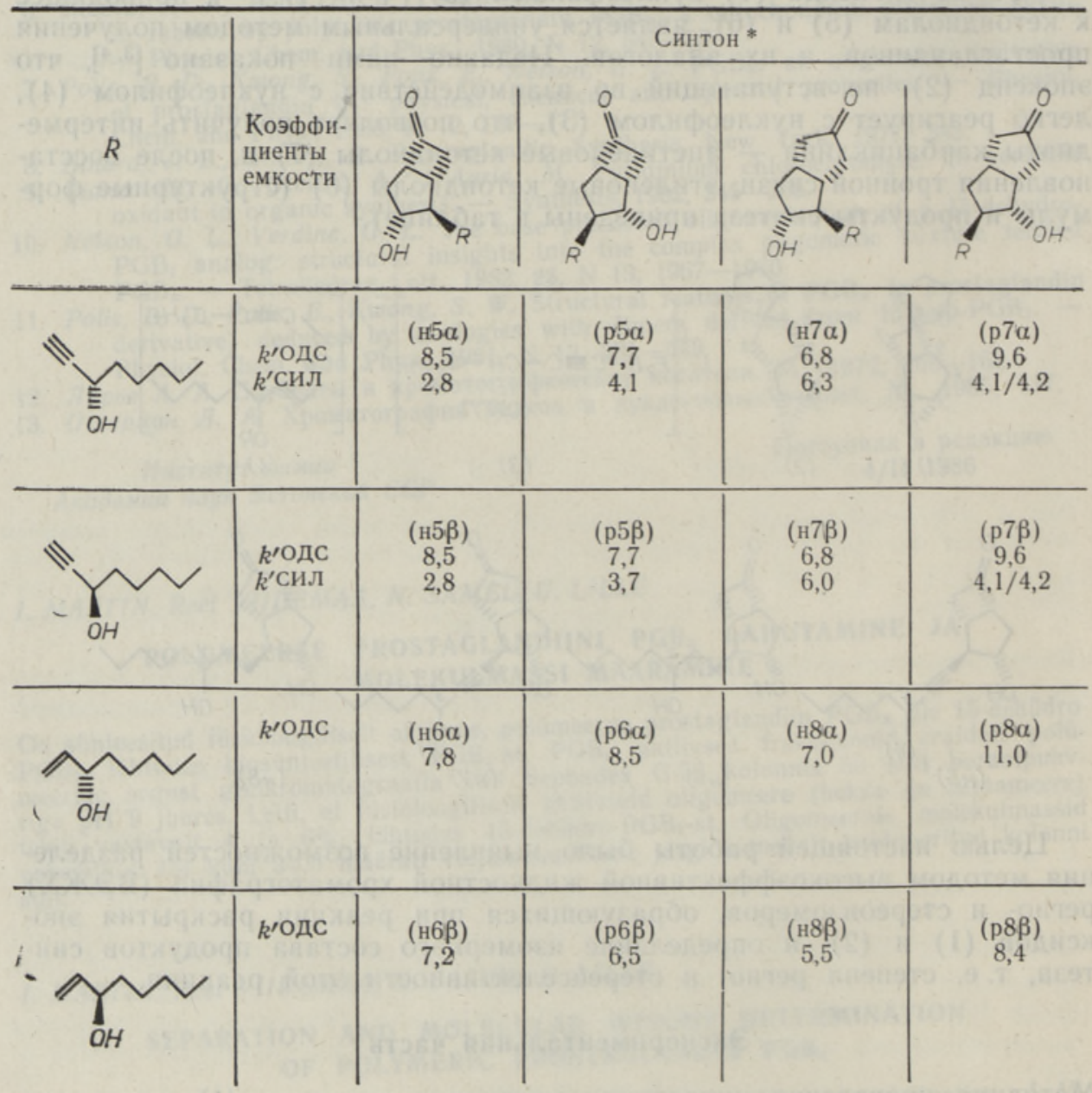

* н - продукт нормального присоединения, приводящий к простанондам с природным расположением $\omega$-цепи; р - продукт, приводящий к региоизомерам по $\omega$-цепи простаноидов. 
Методика превращения ацетиленовых кетондиолов (5) и (7) в этиленовые кетондиолы (6) и (8). 2 мг 2-экзо-(3-гидрокси-окт-1-инил)-3эндо-гидрокси-бицикло[3.3.0]октан-7-она (кетондиола (7)) растворяли в 6 мл бензола, добавляли 50 мкл этиленгликоля и 1 мг $n$-толуолсульфокислоты и перемешивали при $80^{\circ} \mathrm{C}$ в течение 3 ч. К реакционной смеси добавляли одну каплю триэтиламина, сольвент отгоняли. Полученный остаток растворяли в 5,5 мл ТГФ, добавляли 10 мг $\mathrm{LiAlH}_{4}$ и перемешивали при $70^{\circ} \mathrm{C}$ в течение 10 ч. Потом добавляли 1 мл этилацетата и $10 \%$-ный раствор $\mathrm{NH}_{4} \mathrm{Cl}$. Продукт экстрагировали этилацетатом, дважды промывали насыщенным раствором $\mathrm{NaCl}$ и сушили над $\mathrm{Na}_{2} \mathrm{SO}_{4}$. После отгонки растворителя продукт деблокировали смесью ацетонитрил:вода:2N $\mathrm{H}_{2} \mathrm{SO}_{4}(10: 4: 1)$ при комнатной температуре, в течение 20 ч. После нейтрализации, экстракции и отгонки растворителей получили пробы для анализа.

Хроматографирование. Для измерений использовали жидкостный хроматограф «Du Pont 8845» (США) с двумя детекторами - ультрафиолетовым (при 208-210 нм) и рефрактометрическим (отражающим с $20 \%$-ной точностью весовые соотношения продуктов [5]), чтобы полнее выявить из смеси с сильно поглощающими примесями промежуточные соединения синтеза простагландинов, слабо поглощающие в УФобласти.

Из многочисленных элюентов для разделения продуктов синтеза мы выбрали для силикагелевой колонки смесь гексана с изопропанолом, а для обращенно-фазной колонки - смесь воды с ацетонитрилом (структурные формулы и коэффициенты емкости $\left(k^{\prime}\right)$ изученных соединений приведены в таблице).

Ацетонитрил и изопропанол перед применением ректифицировали для увеличения УФ-пропускаемости при 208-210 нм. Гексан использовали без очистки. Коэффициенты емкости вычисляли по [].

\section{Обсуждение результатов}

Раскрытие эпоксида (1) купратом (4) с тетрагидропиранильной защитой приводит после снятия блокирующих группировок к образованию изомерных кетондиолов (6). Эти соединения хорошо разделяются на колонке с Зорбаксом ОДС. Порядок их элюирования следующий: $(\mathrm{p} 6 \beta),(н 6 \beta), \quad(н 6 \alpha)$ и $(\mathrm{p} 6 \alpha)$ (см. таблицу). В данном случае из $\alpha$-соединений раньше выходит н-изомер $\left(k_{\mathrm{H}}^{\prime \text { Одс }}<k_{\mathrm{p}}^{\prime \text { Одс }}\right)$, а из $\beta$-соединений $-\mathrm{p}$-изомер $\left(k_{\mathrm{p}}^{\prime \text { одс }}<k_{\mathrm{H}}^{\text {одд }}\right)$. Соотношение региоизомеров (н6) и (р6) составляет 4:1 [2]. Региоселективность раскрытия эпоксидного цикла «мягкими» основаниями определяется в основном электрофильностью углеродных атомов эпоксида и стерическими факторами [ ${ }^{7,8}$. Поскольку в эпоксиде (1) различие химических сдвигов ядер С2 и С3 в спектре ЯМР ${ }^{13} \mathrm{C}$ довольно значительно $(65,4$ и 61,1 м. д. соответственно), возможно существенное различие и в их электрофильности. Стерически оба углеродных атома хорошо доступны для атаки типа $\mathrm{S}_{\mathrm{N}} 2$, что, однако, не исключает возможности специфически координационного влияния кислородных атомов в эпоксиде (1) на купрат, что определяет региоселективность присоединения.

Соотношение $\alpha$ - и $\beta$-изомеров было $1: 1$ для обоих региоизомеров, что указывает на полное отсутствие стереоселективности по отношению к гидроксилу у СЗ’ в данной реакции. Замена тетрагидропиранильной группы на объемную ахиральную диметил-трет-бутилсилильную не влияет на регио- и стереоселективность этой реакции.

В случае раскрытия эпоксида (1) боратным реагентом (3) разделение продуктов на колонке с Зорбаксом ОДС достигнуто лишь для 
региоизомеров ацетиленовых кетондииолов (р5) и (н5). Стереоизомеры по гидроксилу у С 3 ' $(5 \alpha)$ и $(5 \beta)$ не поддаются разделению, как и в случае аналогичных ацетиленовых лактондиолов и простагландинов $\left[{ }^{9,10}\right]$. Соотношение региоизомеров (н5) и (р5) составляет от $3: 2$ до $4: 2$ (рис. 1) в разных экспериментах. Зависимость соотношения этих региоизомеров от условий проведения реакции требует дальнейшего уточнения. Снижение региоселективности при переходе от купратных к боратным реагентам должно быть связано с меньшей избирательностью данного нуклеофила, возможно, за счет координации «жесткой» кислоты Льюиса $\left(\mathrm{BF}_{3}\right)$ в ходе реакции с эпоксидным кис-

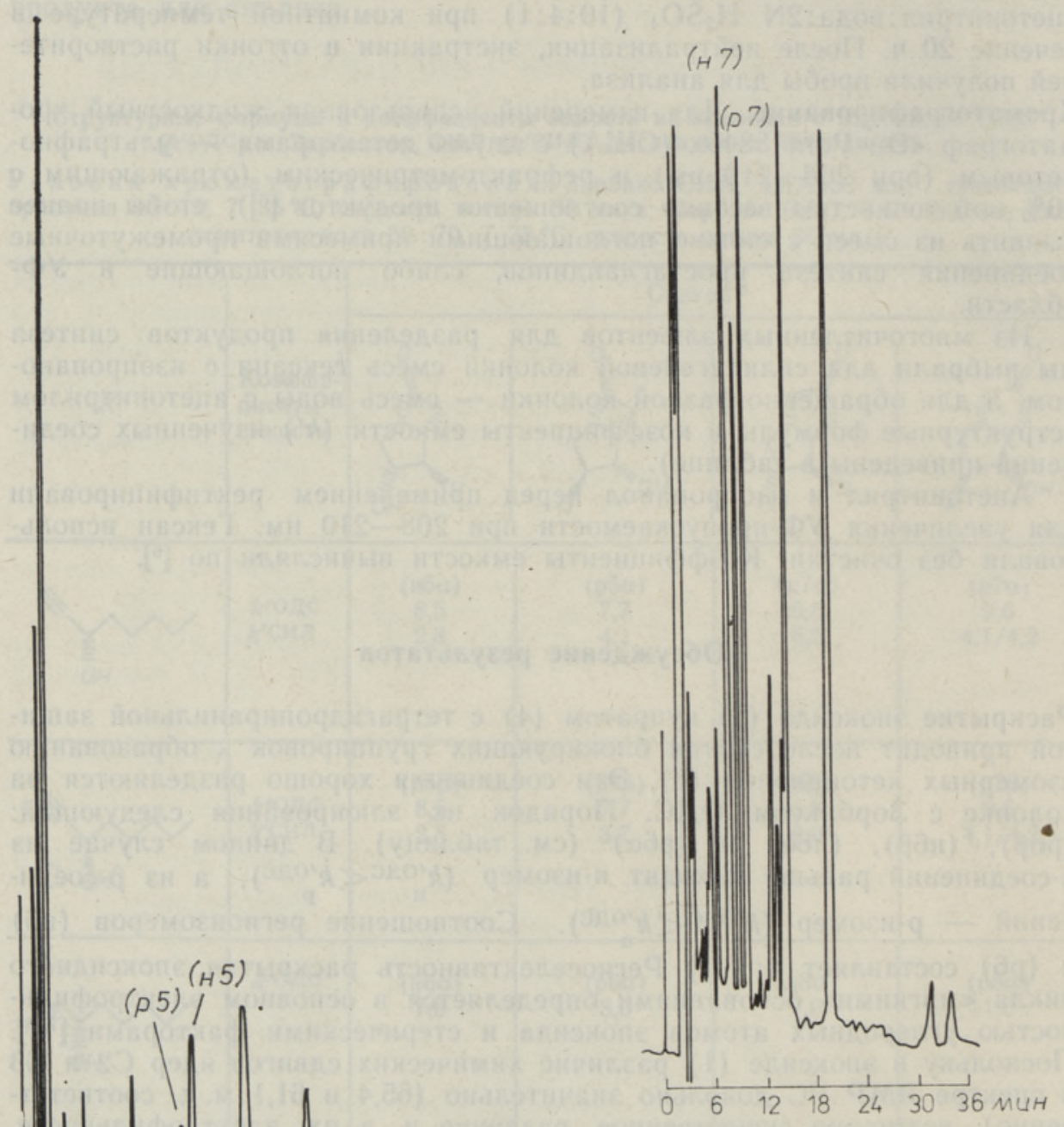

Рис. 2. Хроматограмма соотношения соединений (н7) и (p7). Подвижная фаза - ацетонитрил : вода $40: 60$. Остальные условия см. в подписи к рис. 1 .

Рис. 1. Хроматограмма соотношения соединений (н5) и (р5). Условия: колонка Зорбакс ОДС, 4,6×150 мм, подвижная фаза - ацетонитрил: вода $30: 70$, скорость потока - 36 мл/ч, температура колонки - $35^{\circ} \mathrm{C}$, УФ-детектирование при 208 нм, чувствительность - 0,16 ед. абсорбции по всей шкале, скорость ленты - 10 см/ч. 
лородом субстрата, снижающей величину разницы в электрофильности реакционных центров [7].

Эпоксид (2), неактивный по отношению к купратному реагенту, легко реагирует с боратом (3) - выход ацетиленовых кетондиолов (7) достигает $78 \%\left[{ }^{4}\right]$. Как и в предыдущем случае, из этих соединений разделяются на колонке с Зорбаксом ОДС лишь региоизомеры (н7) и $(\mathrm{p} 7)$, в то время как $(7 \alpha)$ - и $(7 \beta)$-изомеры не делятся (рис. 2). Соотношение региоизомеров (н7) и (p7) составляет 1:1. Отсутствие региоселективности в данном случае не удивительно, если учесть очень маленькое различие в химических сдвигах С2 и С3 $(62,0$ и 62,4 м. д.
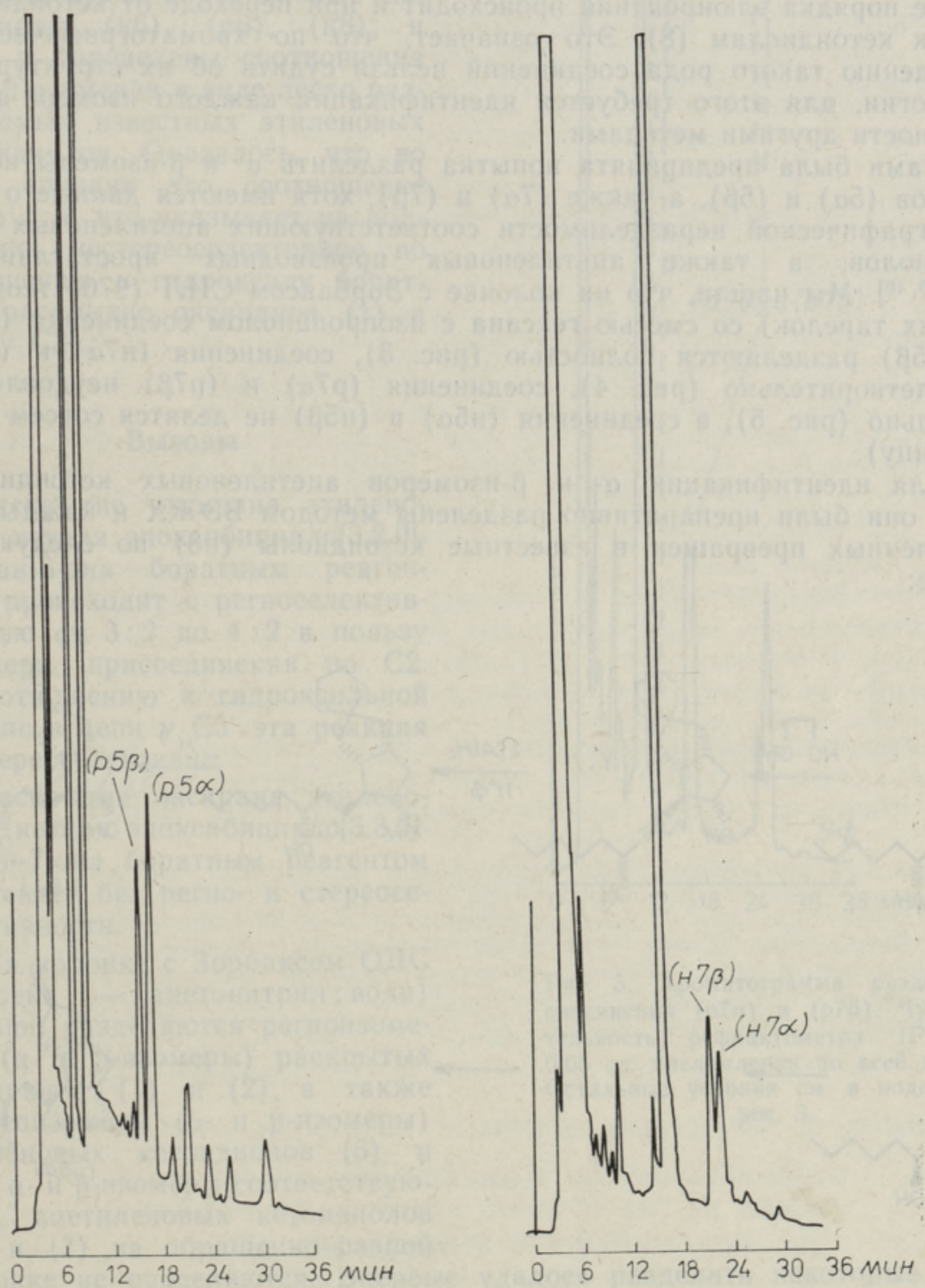

Рис, 3. Хроматограмма разделения соединений (р5 $\alpha)$ и (р5 $\beta)$. Условия: колонка Зорбакс СИЛ, 4,6×150 мм, подвижная фаза - гексан : изопропанол 90: 10, скорость потока - 36 мл/ч, температура колонки - $35^{\circ} \mathrm{C}$, детектирование - УФ 210 нм, чувствительность - 0,16 ед. абсорбции по всей шкале, скорость ленты - 10 см/ч.

Рис. 4. Хроматограмма разделения соединений $($ н $7 \alpha)$ и (н7 $\beta)$. Условия см. в подписи к рис, 3 . 
соответственно) в эпоксиде (2), свидетельствующее о небольшом различии в электрофильности этих углеродов. Кроме того, снизить селективность этой реакции может и фактор координации эпоксидной функциональной группы $\mathrm{c} \mathrm{BF}_{3}$, как и в боратной реакции с эпоксидом (1). В. обоих случаях стерические влияния не должны быть велики, поскольку оба реакционных центра в обоих эпоксидах доступны для атаки типа $\mathrm{S}_{\mathrm{N}} 2$.

Важно отметить, что при переходе от кетондиолов (5) к кетондиолам (7) меняется порядок элюирования н- и р-изомеров на колонке с Зорбаксом ОДС $\left(k_{5 \mathrm{p}}^{\prime \text { Одс }}<k_{5 \mathrm{H}}^{\prime \text { ОдС }}\right.$, а $\left.k_{7 \mathrm{p}}^{\prime \text { Одс }}>k_{7 \mathrm{H}}^{\prime \text { ОдС }}\right)$. Аналогичное изменение порядка элюирования происходит и при переходе от кетондиолов (6) к кетондиолам (8). Это означает, что по хроматографическому поведению такого рода соединений нельзя судить об их структуре по аналогии, для этого требуется идентификация каждого изомера в отдельности другими методами.

Нами была предпринята попытка разделить $\alpha$ - и $\beta$-изомеры кетондиолов $(5 \alpha)$ и $(5 \beta)$, а также $(7 \alpha)$ и $(7 \beta)$, хотя имеются данные о хроматографической неразделимости соответствующих ащетиленовых лактондиолов, а также ацетиленовых производных простагландина $\mathrm{F}_{2 \alpha}\left[{ }^{9,10}\right]$. Мы нашли, что на колонке с Зорбаксом СИЛ (9700 теоретических тарелок) со смесью гексана с изопропанолом соединения ( $55 \alpha$ ) и (р5 $\beta)$ разделяются полностью (рис. 3), соединения (н7 $\alpha)$ и (н7 $\beta)$

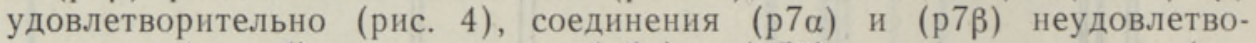
рительно (рис. 5), а соединения (н5 $\alpha)$ и (н5 $\beta$ ) не делятся совсем (см. таблицу).

Для идентификации $\alpha$ - и $\beta$-изомеров ацетиленовых кетондиолов (н7) они были препаративно разделены методом ВЭЖХ и каждый из полученных превращен в известные кетондиолы (н8) по следующей схеме:
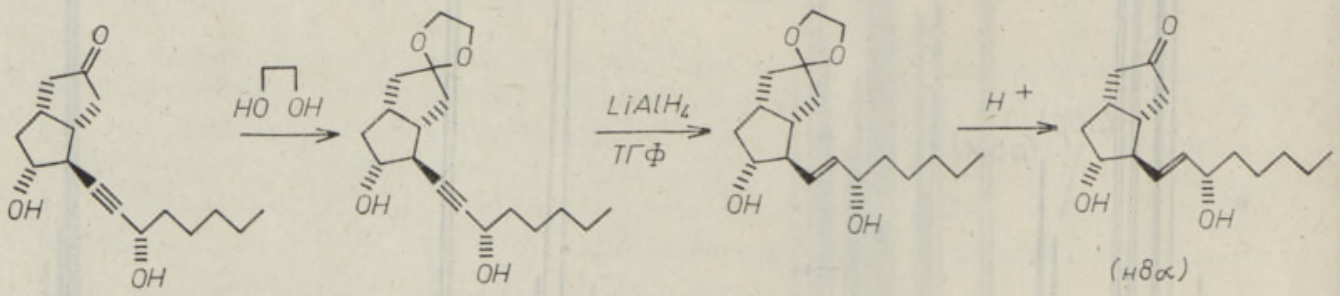

$(H 7 \alpha)$
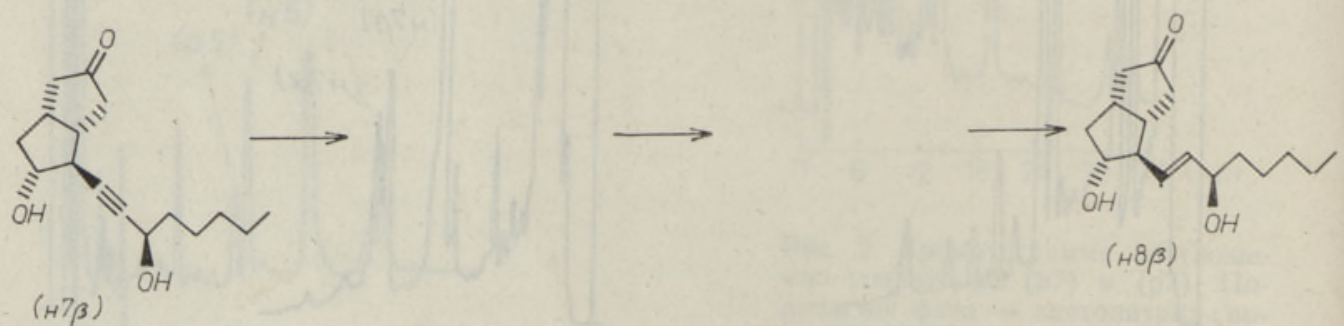

$(\mu \beta \beta)$

Аналогично были идентифицированы $\alpha$ - и $\beta$-изомеры соединения (p5). Мы нашли, что $\alpha$ - и $\beta$-изомеры ацетиленовых кетондиолов элюируют на силикагеле в том же порядке, что и соответствующие изомеры этиленовых кетондиолов. На основе полученных результатов можно сделать вывод, что для биологических испытаний можно получить небольшие количества $\alpha$ - и $\beta$-изомеров некоторых ацетиленовых аналогов 
карбоциклина путем препаративного разделения на силикагеле их кетондиоловых синтонов.

Чтобы установить степень стереоселективности реакции боратного раскрытия эпоксидов по отношению к гидроксилу у С3,' смеси $\alpha$ - и $\beta$-изомеров ацетиленовых кетондиолов (н5), (p5), (н7) и (p7) были превращены в соответствующие этиленовые кетондиолы (н6), (p6), (н8) и (p8) и определены соотношения $\alpha$-и $\beta$-изомеров в виде легко разделяемых известных этиленовых кетондиолов. Оказалось, что во всех случаях это соотношение было $1: 1$, что указывает на полностью нестереоселективное по отношению к гидроксилу боратное раскрытие оксиранов (1) и (2) y C3'.

\section{Выводы}

1. Раскрытие оксирана этиленового кеталя эпоксибицикло[3.2.0]гептан-6-она боратным реагентом происходит с региоселективностью от $3: 2$ до $4: 2$ в пользу изомера присоединения по С2. По отношению к гидроксильной группе в цепи у С3' эта реакция нестереоселективна.

2. Раскрытие оксирана этиленового кеталя эпоксибицикло[3.3.0]октан-7-она боратным реагентом протекает без регио- и стереоселективности.

3. На колонке с Зорбаксом ОДС (элюент - ацетонитрил: вода) хорошо разделяются региоизомеры (н- и р-изомеры) раскрытых оксиранов (1) и (2), а также стереоизомеры ( $\alpha$ - и $\beta$-изомеры $)$ этиленовых кетондиолов (6) и (8). $\alpha$-и $\beta$-изомеры соответствующих ацетиленовых кетондиолов

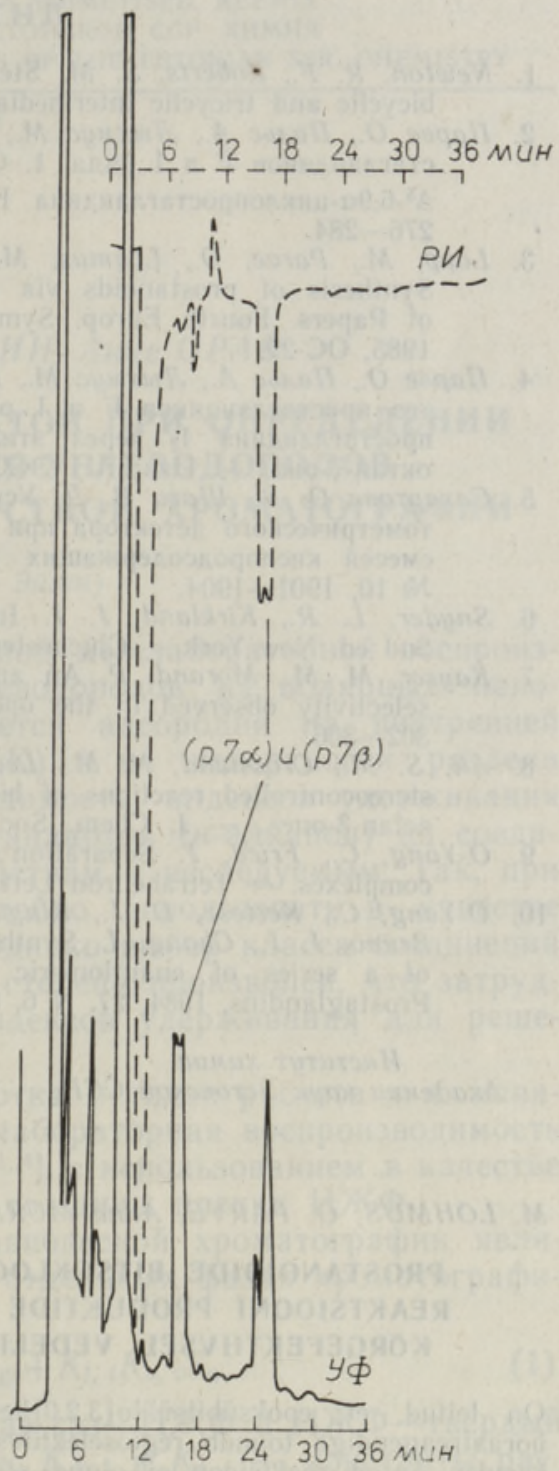

Рис. 5. Хроматограмма разделения соединений $(p 7 \alpha)$ и $(p 7 \beta)$. Чувствительность рефрактометра (РИ) 0,05 ед. преломления по всей шкале. Остальные условия см. в подписи к рис. 3.
(5) и (7) на обращенно-фазной

колонке не разделяются. Впервые удалось разделить некоторые $\boldsymbol{\alpha}$ - и $\beta$-изомеры ацетиленовых кетондиолов (5) и (7) на силикагелевой колонке (элюент - гексан : изопропанол).

4. Региоселективность раскрытия оксирана этиленового кеталя эпоксибицикло[3.2.0]гептан-6-она при переходе от купратных реагентов к боратным уменьшается, причины этого явления требуют дальнейшего изучения. 
1. Newton, R. F., Roberts, S. M. Steric control in prostaglandin synthesis involving, bicyclic and tricyclic intermediates. - Tetrahedron, 1980, 36, N 15, 2163-2196.

2. Парве О., Пальс А., Лыхмус М., Вялимяэ Т., Лопп М., Лилле Ю. Синтез простагландинов $\mathrm{F}$ и I ряда. 1. Синтез $( \pm)$ простагландина $\mathrm{F}_{2 \alpha}$ и $( \pm) 9$-дезожси$\Delta^{5}-6,9 \alpha$-циклопростагландина $\mathrm{F}_{1}$. - Изв. АН ЭССР. Хим., 1985, 34, № 4,. $276-284$

3. Lopp, M., Parve, O., Lōhmus, M., Müraus, A., Pals, A., Välimäe, T., Lille, Đ. Synthesis of prostanoids via alkynyl borate oxirane opening: - In: Abstrt. of Papers. Fourth Europ. Symp. on Organic Chem. Aix-en-Provence (France), 1985 , OC-29.

4. Парве О., Пальс А., Лыхмус М., Вялимяэ Т., Лахе Л., Лопп М., Лилле Ю. Синтез простагландинов F и I ряда. 2. Синтез ( \pm ) 13,14-дидегидро-6,9 $\alpha$-метанопростагландина $\mathrm{I}_{2}$ через этиленовый кеталь 2,3-эндо-эпоксибицикло [3.3.0]октан-7-она. - Изв. АН ЭССР. Хим., 1985, 34, № 4, 285-291.

5. Сахартова O. В., Шатц В. Д. Усредненный калибровочный коэффициент рефрактометрического детектора при высокоэффективной жидкостной хроматографии смесей кислородсодержащих соединений. - Ж. анал. хим., 1984, XXXIX, № 10, 1901-1904.

6. Snyder, L. R., Kirkland, J. J. Introduction to Modern Liquid Chromatography. 2nd ed. New York - Chichester, et al., 1979, 22-43.

7. Kayser, M. M., Morand, P. An analysis of the factors contributing to the regioselectivity observed in the opening of oxiranes. - Can. J. Chem., 1980, 58, 302-306.

8. Ali, S. M., Crossland, N. M., Lee, T. V., Roberts, S. M., Newton, R. F. Some stereocontrolled reactions of bicyclo [3.2.0]heptan-6-ones and 2-oxabicyclo [3.3.0]octan-3-ones. - J. Chem. Soc. Perkin Trans. I, 1979, N 1, 122-125.

9. O-Yang, C., Fried, J. Separation of acetylenic prostaglandin isomers as cobalt complexes. - Tetrahedron Lett., 1983, 24, N 25, 2533-2536.

10. O-Yang, C., Kertesz, D. J., Kluge, A. P., Kuenzler, P., Li, T., Marx, M. M., Bruno, J. J., Chang, L. Synthesis and platelet aggregation inhibition activity of a series of enantiomeric bicyclo[3.2.0] heptane-6-oximinoacetic acids. Prostaglandins, 1984, 27, N 6, 851-863.
Ннститут химии
Академии наук Эстонской ССР
Поступила в редакцию 10/I 1986

\section{LOHMUS, O. PARVE, Anne MURAUS, T. KANGER, M. LOPP, O. LILLE \\ PROSTANOIDIDE BITSUKLOOKSIRAANSETE SUNTONITE AVAMIS- REAKTSIOONI PRODUKTIDE ISOMEERSE KOOSTISE MÄARAMINE KORGEFEKTIIVSEL VEDELIKKROMATOGRAAFILISEL MEETODIL}

On leitud, et epoksübitsüklo[3.2.0]heptaan-6-ooni etüleenketaali oksiraani avamine boraatreagendiga toimub regioselektiivsusega $3: 2$ kuni $4: 2$ 2-asendatud liitumisprodukti kasuks. Antud reaktsioon ei olnud stereoselektiivne $3^{\prime}$-asendis hüdroksüülrühma sisaldavate kõrvalahelate liitumise suhtes. Tehti kindlaks, et epoksiidi avamisel boraatreagendiga toimub regioselektiivsuse vähenemine, võrreldes tema avamisega kupraatreagendiga, $j a$ et epoksübitsüklo[3.3.0] oktaan-7-ooni etüleenketaali oksiraani avamisel sama boraatreagendiga puudub nii regio- kui ka stereoselektiivsus.

\section{LOHMUS, O. PARVE, Anne MURAUS, T. KANGER, M. LOPP, O. LILLE}

\section{DETERMINATION OF IZOMERIZATION OF PRODUCTS FORMED IN THE OPENING REACTION OF PROSTANOID BICYCLO-OXIRANE SYNTHONS BY HPLC}

It was ascertained that the oxirane opening of ethylene ketale of epoxybicyclo[3.2.0] heptane-6-one proceeds with a regioselectivity of $3: 2$ to $4: 2$ for a 2-substituted addition product. This reaction is not stereoselective in terms of addition of the side chains containing hydroxylic groups in the $3^{\prime}$-position. It was established that stereoselectivity is reduced by the opening of the given epoxide with a borate reagent, as compared with the opening with a cuprate reagent.

The oxirane opening of ethylene ketale of epoxybicyclo[3.3.0]-octane-7-one with the same borate reagent was found to lack both regioselectivity and stereoselectivity. 